\title{
REVITALISASI KONSERVASI TOGA (Tanaman Obat Keluarga) UNTUK MEMBANGUN WISATA EDUKASI DALAM MENINGKATKAN EKONOMI HIJAU
}

\author{
Oleh: \\ Vega Candra Dinata ${ }^{1}$, Dhita Ayu Permata Sari ${ }^{2}$ \\ Jurusan Pendidikan Olahraga, Fakultas IImu Olahraga, Universitas Negeri Surabaya \\ vegacandra@unesa.ac.id
}

\begin{abstract}
Abstrak
Kondisi alam Desa Kebontunggul Kecamatan Gondang Kabupaten Mojokerto memiliki Landscape alam yang alami dan pernah menjadi wilayah unggulan Toga (Tanaman Obat Keluarga) hingga meraih juara Tingkat Nasional Tahun 2016. Kurangnya perhatian terhadap dukungan dari pihak-pihak terkait program pelestarian Toga menjadi terabaikan. Sementara itu, budidaya tanaman obatan-obatan mempunyai prospek yang menjanjikan untuk dapat meningkatan perekonomian masyarakat. Tanaman obat telah dibudidayakan oleh masyarakat Desa Kebontunggul, terutama jenis yang masih langka. Seiring dengan program Desa Kebontunggul untuk memaksimalkan potensi alam sebagai desa wisata alam, maka konservasi Toga sangatlah tepat untuk meningkatkan pencitraan publik sehingga dapat meningkatkan perekonomian masyarakat (perekonomian hijau). Prospek wilayah desa Kebontunggul ke depan akan dikembangkan menjadi wahana edukasi untuk mengenal jenis-jenis tanaman obat di Indonesia. Kegiatan ini melibatkan masyarakat, stakeholder, mahasiswa, dan pengelola Wisata Lembah Bencirang. Hasil kegiatan ini adalah terwujudnya konservasi toga yang dilengkapi dengan katalog berbagai toga di Wisata Lembah Bencirang. Jumlah toga yang teridentifikasi di desa sebanyak 76 jenis toga dengan jumlah seluruh pohon sebanyak 1022 pohon yang tersebar di 4 dusun yang berbeda, yaitu Dusun Sengon, Dusun Kudur, Dusun Penunggulungan, dan Dusun Jemanik. Toga yang dibudidayakan khusus di greenhouse sebanyak 20 jenis toga. Saran untuk pengembangan konservasi toga sebagai wujud wisata edukasi adalah mengembangkan rencana bisnis untuk mempromosikan konservasi toga dan produk-produk toga yang dapat dijual. Warga merespons positif terhadap kegiatan ini yang terlihat dari $92 \%$ warga mendukung, $97 \%$ warga memahami tema kegiatan, $100 \%$ warga merasakan kebermanfaatan kegiatan dan berharap kegiatan ini dilanjutkan di tahun berikutnya....
\end{abstract}

Kata Kunci: Konservasi Toga, Wisata Edukasi, Ekonomi Hijau

\section{Abstract}

The condition of Kebontunggul Village, Gondang Subdistrict, Mojokerto Regency has a natural landscape and was once the flagship area of the Toga (Family Medicinal Plant) until it won the National Level in 2016. The lack of attention to the support of the parties make the preservation of the Toga program ignored. Meanwhile, the cultivation of medicinal plants has promising prospects for improving the community's economy. Medicinal plants have been cultivated by the people of Kebontunggul Village, especially those which are still rare. Along with the Kebontunggul Village program to maximize the potential of nature as a natural tourism village, the conservation of Toga is very appropriate to improve public imagery so as to improve the community's economy (green economy). The prospect of Kebontunggul village area in the future will be developed into an educational vehicle to get to know the types of medicinal plants in Indonesia. This activity involves the community, stakeholders, students, and managers of Bencirang Valley Tourism. The result of this activity showed by toga conservation construction which is equipped with a catalog of various toga in Bencirang Valley Tourism. The result of this activity is the realization of toga conservation which is equipped with a catalog of various toga at Bencirang Valley Tourism. The number of toga identified in the village is 76 types of toga with a total of 1022 trees spread over 4 different villages, namely Sengon Village, Kudur Village, Penunggulungan Village, and Jemanik Village. There are 20 types of toga specially cultivated in greenhouses. Some suggestions for future program are develop a business plan to promote the conservation of toga and toga products that can be sold. The residents responded positively to this activity, as seen from $92 \%$ of the residents supporting, $97 \%$ of the residents understood the theme of the activity, $100 \%$ of the residents felt the benefits of the activity and hoped that the activity would continue the following year.

Keywords: Toga (Family Medical Plant) Conservation, Educational Tour, Green Economic 


\section{PENDAHULUAN}

Desa Kebontunggul berada dalam wilayah administrasi Kecamatan Gondang Kabupaten Mojokerto, Jawa Timur. Monografi desa Kebontunggul merupakan daerah dataran tinggi dengan ketinggian $400 \mathrm{~m}$ dpl. Desa Kebontunggul memiliki luas wilayah sebesar 263.215 ha, yang terbagi menjadi terbagi menjadi 4 dusun, antara lain: (1) Dusun Penunggulan; (2) Dusun Kudur; (3) Dusun Sengon; dan (4) Dusun Jemanik. Sedangkan jarak dari Kota Mojokerto berkisar $23 \mathrm{~km}$.

Dari luas tersebut 168 ha merupakan tanah pertanian padi, 150 ha pertanian palawija, 48 ha pertanian sayuran, 74,6 ha pertanian buah dan 5 ha daerah perkebunan. Jumlah penduduk desa Kebontunggul sebanyak 1.766 jiwa yang terdiri atas 792 jiwa laki-laki dan 874 jiwa perempuan. Sebagian besar penduduk desa Kebontunggul memeluk agama islam yaitu sebanyak $97,1 \%$, sedangkan mata pencaharian penduduknya sebagian besar bertani dan berternak.

Desa Kebontunggul dengan keanekaragaman hasil bumi, hasil hasta karya warga dan sebagainya. Sebagai salah satu desa yang dikaruniai nilai lebih dibanding dengan Desa lain di Kabupaten Mojokerto. Dengan hamparan yang meliputi sawah, ladang dan perbukitan yang mengelilingi desa Kebontunggul,

Salah satu permasalahan nyata yang sedang dihadapi warga desa Kebontunggul, Kecamatan Gondang adalah kurang pengetahuan pemanfaatan tanaman obat sehingga gerakan pelestarian Toga yang menjadi salah satu icon dari desa ini kurang mendapatkan respon dari masyarakat, konon sebelumnya desa ini sudah pernah meraih juara Nasional Asman Toga. Disamping itu, masyarakat juga kurang mengetahui manfaat jenis-jenis tanaman Toga tersebut, seperti manfaat mentimun untuk kecantikan. Masyarakat desa Kebontunggul pada umumnya hanya mengetahui mentimun sebagai bahan makanan saja, padahal selain untuk bahan makanan, mentimun dapat dimanfaatkan sebagai produk kecantikan alami yakni masker wajah, dan lain-lain.

Tanaman obat sudah banyak sekali digunakan oleh manusia sejak zaman dahulu. Bahkan dipercaya mempunyai khasiat yang lebih ampuh daripada obatobat dokter. Seiring dengan perkembangan jaman dan semakin meningkatnya pengetahuan manusia tentang farmakologi dan ilmu kedokteran, banyak masyarakat yang beralih ke obat-obatan dokter karena lebih mempercayai obat-obatan kimia yang telah teruji khasiatnya secara laboratorium, dibandingkan dengan obat tradisional yang banyak belum bisa dibuktikan secara laboratorium.

Banyak bagian tumbuhan yang bisa digunakan sebagai obat, diantaranya adalah bagian buah, batang, daun, dan akar atau umbi. Oleh karena pentingnya tanaman-tanaman obat tersebut maka perlu kita mempelajarinya dengan baik sehingga dapat berdaya guna bagi kita.

Program KKN-PPM yang dilaksanakan di Desa Kebontunggul merupakan salah satu keberlanjutan (sustainable) dari kegiatan KKN Reguler Unesa tahun 2017 yang dilaksanakan selama 1 (satu) tahun terbagi menjadi 4 gelombang dengan desa yang sama. Tahapan proses sampai pada capaian masyarakat mandiri.

Hasil survey oleh tim pengusul bahwa pada tiap-tiap dusun terdapat Toga dan kondisinya juga sama kurang terawat meski ada beberapa tanaman Toga yang masih dibutuhkan, dan juga berpendapat untuk memenuhi kewajiban dari kepala desa sebagai warga setiap dusun harus ada Toga. Dengan demikian rumusan masalah dapat diuraikan sebagai berikut:

a. Bagaimana caranya membudidayakan Toga dengan baik dan benar?

b. Bagaimana caranya mengembangkan pengetahuan masyarakat terhadap kemanfaatan tanaman obat-obatan?

c. Bagaimana cara mempromosikan kepada publik agar desa Kebontunggul dikena sebagai tempat wisata alam (Toga)?

\section{METODE}

\section{Strategi Penyelesaian Masalah}

Strategi penyelesaian permasalahan yang diterapkan terangkum dalam Tabel 1 dengan uraian sebagai berikut.

a. Menata ulang kondisi Toga yang sudah ada, karena Toga sebagai pusat konservasi maka perlu adanya greenhouse untuk melindungi tanam-tanam agar tidak ditumbuhi liar, dan juga agar perawatannya lebih mudah hingga disaat diperlukan mencari juga lebih mudah. 
b. Greenhouse dengan model penyiraman semiotomatis dapat menghemat tenaga dan air sesuai dengan kebutuhan tanaman. Greenhouse dibuat dengan ukuran sesuai dengan ukuran tanah yang tersedia $(5 \times 10 \mathrm{~m})$ dibangun secara semi permanen, karena lahan yang digunakan adalah lahan milik kas desa dan sewaktuwaktu dapat dipindahkan. Untuk perawatan tanaman obat keluarga disediakan pupuk organik dengan memproduksi sendiri sehingga tidak mengurangi atau mengubah kandungan nutrisi tanaman dan struktur tanah. Setiap tanaman disebutkan anatomi sesuai dengan karakternya dan juga diberikan gambar untuk mempermudah dalam memahami wujud aslinya. Adapun pada tahap proses pembelajaran masyarakat, tiap dusun diminta untuk mengirimkan perwakilan 7 (tujuh) orang per dusun untuk mengikuti pelatihan dan pendampingan cara menaman, merawat, dan memfungsi tiap tanaman sebagai obat c. Untuk mempermudah dalam memahami setiap tanaman obat, perlu dibuatkan katalog nama-nama tanaman. Setiap tanaman disebutkan anatomi sesuai dengan karakternya dan juga diberikan gambar untuk mempermudah dalam memahami wujud aslinya. Adapun pada tahap proses pembelajaran masyarakat, tiap dusun diminta untuk mengirimkan perwakilan 7 (tujuh) orang per dusun untuk mengikuti pelatihan dan pendampingan cara menaman, merawat, dan memfungsi tiap tanaman sebagai obat herbal. Dalam hal pembuatan ramuan obat herbal, tim pengusul bekerjasama dengan ahli herbal Penyuluh Asuhan Mandiri.

d. Sedangkan menjadikan perhatian publik Greenhouse konservasi Toga desa Kebontunggul, perlu adanya promosi produk dikemas dalam bentuk brosur baik dalam bentuk fisik maupun online.

Tabel 1. Peta Penyelesaian Masalah

\begin{tabular}{|c|c|c|c|}
\hline No. & Kegiatan & Target Sasaran & Tindak Lanjut \\
\hline 1. & $\begin{array}{l}\text { Koordinasi dengan } \\
\text { aparat desa } \\
\text { Kebontunggul }\end{array}$ & $\begin{array}{l}\text { a. Tim dan mahasiswa } \\
\text { b. Kepala Desa, perangkat } \\
\text { desa, tokoh masyarakat, dan } \\
\text { masyarakat. }\end{array}$ & $\begin{array}{l}\text { a. Desain Greenhouse. } \\
\text { b. Sosialisi program. } \\
\text { c. Penetapan lokasi } \\
\text { d. Membangun komitmen } \\
\text { kerjasama dalam } \\
\text { pelaksanaan }\end{array}$ \\
\hline 2. & Sosialisasi Program & $\begin{array}{l}\text { a Penyampaian materi bagi } \\
\text { masyarakat } \\
\text { b. Simulasi pembuatan jamu } \\
\text { herbal tingkat dasar. }\end{array}$ & $\begin{array}{l}\text { a. Masyarakat memahami } \\
\text { materi } \\
\text { b. Masyarakat dapat membuat } \\
\text { sendiri }\end{array}$ \\
\hline 3. & Validasi sasaran & $\begin{array}{ll}\text { a. Toga } \\
\text { b. Bahan dan alat }\end{array}$ & $\begin{array}{l}\text { a. Menginventarisasi jenis- } \\
\text { jenis tanaman Toga } \\
\text { b. Ketersediaan air, pupuk, dan } \\
\text { bahan penunjang proses } \\
\text { penanaman dan } \\
\text { pemeliharaan. }\end{array}$ \\
\hline 4. & Aktivitas lapangan & $\begin{array}{l}\text { a. Membagi kelompok } \\
\text { masyarakat, masing- } \\
\text { masing kelompok menjadi } \\
\text { tanggungjawab kelompok } \\
\text { mahasiswa sebagai } \\
\text { pendampingnya. } \\
\text { b. Membagi kelompok kerja } \\
\text { bagi mahasiswa maupun } \\
\text { masyarakat. }\end{array}$ & $\begin{array}{l}\text { a. Masyarakat memahami alur } \\
\text { pekerjaan yang harus } \\
\text { diselesaikan } \\
\text { b. Masyarakat bersinergi } \\
\text { dengan mahasiswa setiap } \\
\text { melaksanakan pekerjaannya }\end{array}$ \\
\hline
\end{tabular}




\begin{tabular}{|c|c|c|c|}
\hline No. & Kegiatan & Target Sasaran & Tindak Lanjut \\
\hline 5. & $\begin{array}{l}\text { Pelatihan dan } \\
\text { Pendampingan }\end{array}$ & $\begin{array}{l}\text { a. Masyarakat dan mahasiswa } \\
\text { mempelajari cara menanam, } \\
\text { merawat, dan memelihara } \\
\text { Toga } \\
\text { b. Masyarakat dan mahasiswa } \\
\text { mempelajari jenis-jenis } \\
\text { tanaman dan manfaatnnya } \\
\text { Toga. }\end{array}$ & $\begin{array}{l}\text { a. Masyarakat melakukan } \\
\text { kegiatan menanam, } \\
\text { merawat, dan memelihara } \\
\text { Toga. } \\
\text { b. Penyusunan buku catalog } \\
\text { Toga. }\end{array}$ \\
\hline 6. & Evaluasi Kegiatan & $\begin{array}{ll}\text { a. } & \text { Penyebaran instrumen } \\
& \text { responden dengan } \\
& \text { masyarakat. } \\
\text { b. Dokumentasi hasil capaian }\end{array}$ & $\begin{array}{l}\text { a. Rumusan hasil evaluasi. } \\
\text { b. Penyempurnaan program. }\end{array}$ \\
\hline 7. & Seminar & $\begin{array}{l}\text { a Pemaparan laporan hasil } \\
\text { b. Masukan dari audien }\end{array}$ & a. Penyusunan draft laporan \\
\hline 8. & Penyusunan laporan & $\begin{array}{l}\text { a. Mengakomodasi dokumen } \\
\text { kegiatan } \\
\text { b. Merivisi isi laporan }\end{array}$ & $\begin{array}{ll}\text { a. Pulikasi jurnal nasional. } \\
\text { b. Publikasi di media masa } \\
\text { cetak. }\end{array}$ \\
\hline
\end{tabular}

Teknologi yang Diterapkan

Teknologi yang diterapkan dalam penyelesaian masalah disesuaikan dengan kondisi lapangan dan diuraikan dalam Tabel 2.

Tabel 2. Teknologi yang Diterapkan

\begin{tabular}{|c|c|c|c|}
\hline No. & Permasalahan & $\begin{array}{l}\text { Teknologi Yang } \\
\text { Diterapkan }\end{array}$ & Output Kegiatan \\
\hline 1. & $\begin{array}{lr}\text { Toga yang } & \text { kurang } \\
\text { menjadi } & \text { perhatian } \\
\text { masyatakat. } & \end{array}$ & $\begin{array}{l}\text { Greenhouse Toga sebagai } \\
\text { pusat konservasi }\end{array}$ & $\begin{array}{l}\text { a. Efektifitas dan efisiensi } \\
\text { perawatan Toga. } \\
\text { b. Keasrian lingkungan } \\
\text { desa. }\end{array}$ \\
\hline 2. & $\begin{array}{l}\text { Tanaman obat-obatan } \\
\text { belum terinventarisasi } \\
\text { jenis dan manfaatnya. }\end{array}$ & Katalog Toga & $\begin{array}{l}\text { Mengklasifikasikan dan } \\
\text { mendeskripsikan jenis dan } \\
\text { manfaat tanaman obat- } \\
\text { obatan. }\end{array}$ \\
\hline 3. & $\begin{array}{l}\text { Berpontensi untuk } \\
\text { destinasi wisata. }\end{array}$ & $\begin{array}{ll}\text { a. } & \text { Media Sosial } \\
\text { b. } & \text { Brosur }\end{array}$ & Publikasi potensi desa \\
\hline
\end{tabular}

\section{Mekanisme Pelaksanaan Kegiatan KKN- PPM}

Kuliah Kerja Nyata-Pembelajaran Pemberdayaan Masyarakat (KKN-PPM) merupakan salah satu kegiatan pengabdian kepada masyarakat dalam bentuk kegiatan KKN sebagai kontribusi universitas bagi masyarat, industri, pemerintah daerah dan kelompok masyarakat secara ekonomi maupuin sosial. Kegiatan ini dilaksanakan oleh Tim PKM KKN-PPM dengan kegiatan KKN yang berbeda dan terpisah dari kegiatan KKN reguler. Waktu pelaksanaan KKN-PPM ini bisa bersamaan dengan waktu kegiatan KKN reguler dan bisa juga menyesuaikan dengan kondisi program KKN-PPM yang dilaksanakan.

Kegiatan KKN-PPM yang dilaksanakan oleh tim PKM dilaksanakan sesuai jadwal $\mathrm{KKN}$ reguler. Mahasiswa yang terlibat dalam pelaksanaan KKN-PPM adalah mahasiswa yang memprogram mata kuliah KKN dan dibimbing oleh Dosen Pembimbing Lapangan (DPL) selama kegiatan berlangsung.

Pelaksanaan dibagi menjadi tiga tahapan, yaitu (1) Persiapan dan pembekalan, (2) Pelaksanaan KKN-PPM, dan (3) Pelaporan. Kegiatan yang telah dilaksanakan adalah kegiatan tahap 1 dan tahap 2. Di setiap kegiatan pelaksanaan KKN-PPM ditindaklanjuti dengan proses monitoring dan 
evaluasi dari Dosen Pembimbing Lapangan (DPL) dengan dokumentasi kegiatan disinkronisasi melalui SIMKKN Unesa. Gambar 1 merupakan alur mekanisme pelaksanaan Program KKN-PPM.

Penyiapan bibit tanaman obat keluarga (toga) Bibit yang akan ditanam disemai terlebih dahulu dan dipersiapkan oleh tim pembantu pelaksana PKM. Bibit disiapkan dan disemai selama dua minggu di lokasi berbeda dari lokasi KKN-PPM. Pengangkutan ke Desa Kebontunggul dilaksanakan setelah greenhouse selesai dibangun.

Rekrutmen mahasiswa dilakukan dengan cara membuka pengumuman untuk seleksi Program KKN-PPM. Rekrutmen dibuka untuk umum bagi mahasiswa Unesa yang berminat dan berdedikasi untuk mengaplikasikan ilmunya dalam membangun Desa Kreatif melalui Konservasi Toga di Desa Kebontunggul. Keseluruhan pendaftar diseleksi berdasarkan bidang keahlian yang dibutuhkan untuk pencapaian tujuan Program KKN-PPM dan motivasi mahasiswa. Hasil seleksi diumumkan melalui SIMKKN Unesa. Mahasiswa yang lolos seleksi secara otomatis terdaftar dalam daftar mahasiswa $\mathrm{KKN}$ di Desa Kebontunggul.

Tim pelaksana KKN-PPM berkoordinasi dengan Kepala Desa, konsultan pembangunan wisata edukasi, dan warga yang ditunjuk oleh Kepala Desa untuk mendampingi program KKN-PPM. Warga memberikan saran terkait penyediaan dan lokasi yang strategis untuk mendirikan greenhouse.

Pendidikan dan pelatihan mahasiswa dilaksanakan pada tanggal 25 Juni 2019. Mahasiswa diberi tugas untuk menyusun program kegiatan KKN-PPM. Program utama kegiatan ini adalah membangun greenhouse dan budidaya tanaman toga yang difokuskan di greenhouse tersebut. Program tambahan yang dirancang oleh mahasiswa meliputi program pendidikan (misalnya bimbingan belajar), bidang kesehatan (misalnya membantu di posyandu saat ada kegiatan desa), dan bidang seni budaya dan agama (misalnya pengajian, pelatihan tari bagi anakanak). Selain itu, Tim Pelaksana PKM, Tim Pembantu Pelaksana PKM, dan Maha-siswa membangun greenhouse di area Wisata Edukasi Mbencirang.

Greenhouse atau rumah kebun khusus yang digunakan untuk tempat menanam tumbuhan atau pembimbitan. Tujuannya untuk memberikan perlindungan dan perawatan secara khususnya, dan manfaatnya tumbuhan dapat termonitoring secara rutin serta kemungkinan kecil terserang oleh hama atau penyakit tumbuhan terutama yang disebarkan melalui angin.

Greenhouse Toga sebagai pusat pemberdayaan masyarakat dipastikan tidak menimbulkan permasalahan yang berdampak, baik secara sosial maupun administrasi lingkungan. Greenhouse untuk pemberdayaan masyarakat dibangun di atas tanah bukan hak milik sebaiknya dibangun dengan model semi permanen. Dibangun dengan model semi permanen setidaknya sewaktu-waktu tanahnya digunakan untuk pengembangan desa dapat dipindahkan dengan mudah, misalnya tanah kas desa, dan lain-lain.

Bahan-bahan yang digunakan adalah bahan yang ramah lingkungan seperti dengan menggunakan kerangka bambu dan tali ijuk, hasilnya akan terlihat kuat dan mempunyai nilai seni. Bagian-bagian bagunan Greenhouse yang pokok antara lain: lantai, atap, dinding, dan kerangka.

Data yang diperoleh dianalisis secara deskriptif kualitatif tentang greenhouse yang telah dibangun dan respon masyarakat terhadap kegiatan.

\section{HASIL DAN PEMBAHASAN \\ Hasil Konservasi Toga}

Hasil pelaksanaan setelah diterap-kannya program KKN-PPM sebagai kontribusi perguruan tinggi kepada mitra sasaran antara lain sebagai berikut.

Teridentifikasi Toga terdata 76 jenis Toga dengan jumlah seluruhnya 1022 pohon yang terbagi di 4 dusun yaitu dusun Sengon sebanyak 244 pohon, dusun Kudur 229, dusun Penunggulan 236 pohon, dan Jemanik 313 pohon. Nama-nama Toga yang ditulis oleh pelaksana sesuai dengan sebutan umum dari masyarakat desa Kebontunggul. Nama-nama Toga tersebut antara lain : Adem Ati, Ajeran, Alpukat, Arbei, Asam Jawa, Belimbing, Belimbing Wulung, Beluntas, Binahong, Brotowali, Bunga Kenop, Ceker Ayam, Cempaka putih, Cempaka putih, Cerme, Ciplukan, Cocor Bebek, Daun Adas (Pulosari), Daun Andong, Daun Bidara (Cendono), Daun Dewa, Daun ller, Daun Sendok, Dlingo (Dringu), Duwet, Ekor Kucing, Gingseng Merah (Korea), Jahe, Jambu Biji Merah, Jarak, Jati Belanda, Jinten, Kapulaga, Katuk, Kayu Manis, Kayu Putih, Keji Beling, Kelor, Kemuning, Kencur, Kitolod Krokot Merah, Kumis Kucing, Kumis Kuning, Kunci, Kunyit/Kunir, Laos, Lavender, Lengkuas, Lidah 
Buaya, Mahkota Dewa, Mengkudu, Meniran, Pacar Air, Patah Tulang, Pecut Kuda, Pleteon, Pohon Secang, Roselia, Salam, Sambangdara, Sambiloto, Sambung Nyowo, Sirih Hijau, Sirih Merah, Sogok Telik, Tanduk Rusa (Kuping Kidang), Tapal Kuda, Teh Belanda, Tempuyung, Temulawak, Turi Merah, Turi Putih, Waru Gunung, Wijayakusuma, Yakun, dan Yodium.

Hasil dari identifikasi Toga masing-masing untuk memberikan identitas diambil dari rekomendasi sumber yang literet. Selanjutnya disusun menjadi sebuah Katalog Toga.

Terwujudnya greenhouse sebagai pusat konservasi Toga. Greenhouse dibangun diatas tanah desa yang berada di kawasan Ekowisata alam Lembah Mbencirang dengan ukuran 5 x 10meter tinggi 3 meter. Kerangka greenhouse dari bambu petung dengan konsep ramah lingkungan. Sedangkan untuk pelindung-nya menggunakan paranet hitam yang menutupi seluruh bagian greenhouse.

Di dalam greenhouse ini budidaya toga diawali dengan 20 jenis toga, yaitu jahe, gingseng merah, laos, kunyit, lengkuas, lidah buaya, salam, sirih hijau, sirih merah, pohon insulin, alpukat, mahkota dewa, mengkudu, sambiloto, teh belanda, tempuyung, temulawak, turi merah, asam jawa, dan keji beling. Gambar 1 menunjukkan foto Sebagian toga yang dibudidaya di greenhouse.

Indikator keberhasilan KKN keberhasilan KKN dapat dilihat dari partisipasi masyarakat terhadap program KKN dan mampu bekerjasama dengan mahasiswa selaku pelaksana program KKN. Disamping itu juga dukungan dari aparat pemerintahan desa, dan tokoh masyarakat desa.

\section{Respon Masyarakat}

Hasil dari sebaran instrument sebanyak 50 eksemplar untuk responden terisi 40 eksemplar. Sedangkan sasaran responden memprioritaskan Perangkat Desa, Karang Taruna, Ibu-Ibu PKK, dan Masyarakat Umum dan pilihannya SS: Sangat Setuju, S: Setuju, KS: Kurang Setuju, STS: Sangat Tidak Setuju.

Berdasarkan hasil tabulasi responden terhadap tanggapan pelaksanan Program KKN PPM Unesa 2019 di desa Kebontunggul maka dihasilkan data pada Tabel 3.

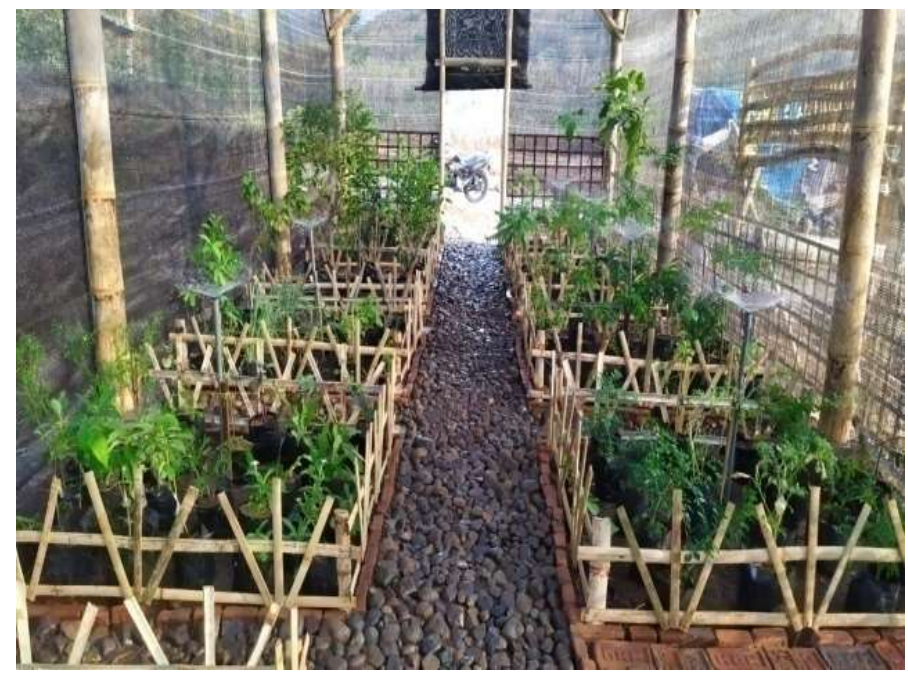

Gambar 1. Greenhouse di Lokasi Destinasi Wisata

Tabel 3. Tabulasi Responden terhadap Pelaksanaan Program KKN PPM Unesa

\begin{tabular}{|c|c|c|c|c|c|}
\hline \multirow[t]{2}{*}{ No. } & \multirow[t]{2}{*}{ Pernyataan } & \multicolumn{4}{|c|}{ Respons } \\
\hline & & SS & $\mathrm{S}$ & KS & STS \\
\hline 1 & $\begin{array}{l}\text { Warga menyukai kehadiran mahasiswa selama pelaksanaan } \\
\text { KKN-PPM di Desa Kebontunggul. }\end{array}$ & 27 & 23 & 0 & 0 \\
\hline 2 & $\begin{array}{l}\text { Warga memahami tema KKN-PPM tentang Ekowisata Edukatif } \\
\text { Konservasi Toga di Lembah Mbencirang. }\end{array}$ & 17 & 21 & 1 & 0 \\
\hline 3 & $\begin{array}{l}\text { Warga mendukung dan berpartisipasi pelaksanaan KKN-PPM } \\
\text { di Desa Kebontunggul. }\end{array}$ & 22 & 15 & 3 & 0 \\
\hline
\end{tabular}




\begin{tabular}{llcccc}
\hline 4 & $\begin{array}{l}\text { Greenhouse Toga bermanfaat bagi perkembangan Desa } \\
\text { Kebontunggul. }\end{array}$ & 28 & 12 & 0 & 0 \\
\hline 5 & $\begin{array}{l}\text { Program KKN-PPM ini diharapkan dapat dilanjutkan di tahun } \\
\text { berikutnya. }\end{array}$ & 24 & 16 & 0 & 0 \\
\hline 6 & $\begin{array}{l}\text { Warga menilai bahwa selama mahasiswa di desa bersikap } \\
\text { baik, sopan, dan terlibat aktif dalam kegiatan sosial } \\
\text { masyarakat. }\end{array}$ & 11 & 0 & 0 \\
\hline 7 & $\begin{array}{l}\text { Dalam pelaksanaan kegiatan mahasiswa selalu berkoordinasi } \\
\text { dengan kepala desa dan perangkat desa. }\end{array}$ & 22 & 0 & 0 \\
\hline
\end{tabular}

Hasil tabulasi responsden pada Tabel 3 dirangkum dalam diagram pada Gambar 2. Berdasarkan Tabel 3 kehadiran mahasiswa di lingkungan masyarakat diterima dengan baik mulai dari penerimaan di lokasi sampai proses pemulangan tidak terdapat permasalahan signifikan.

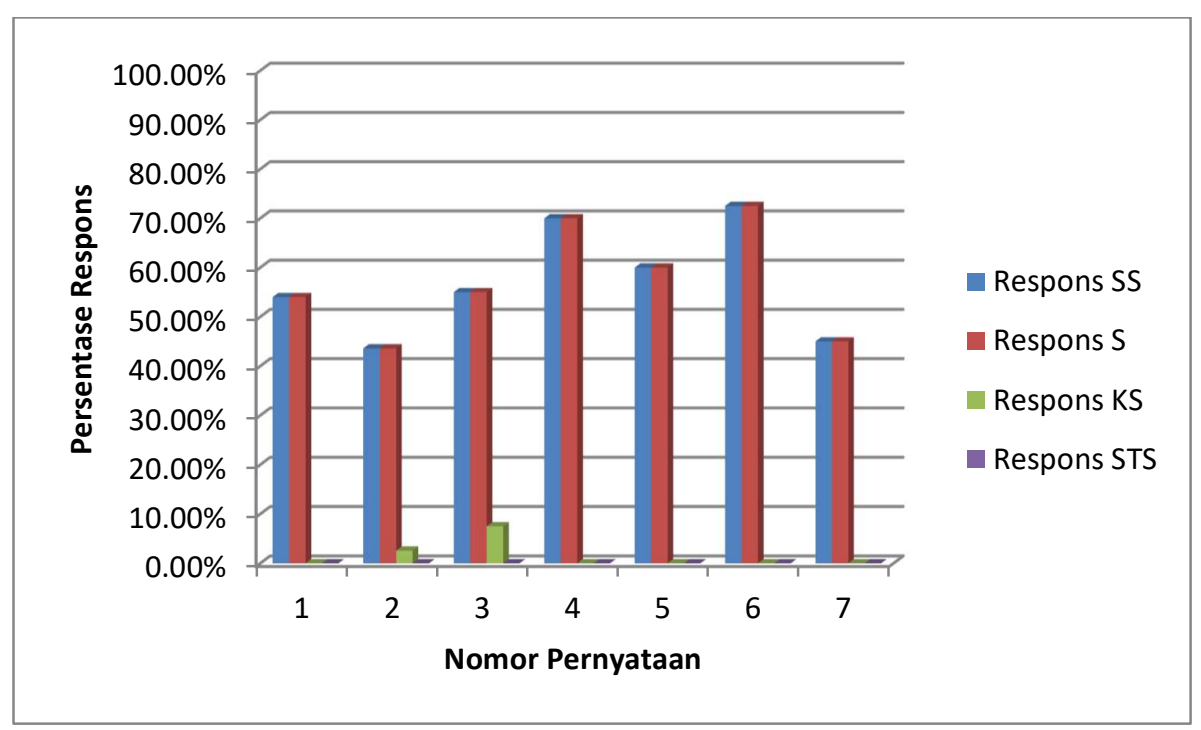

Gambar 2. Grafik Respons Warga

Pada prinsipnya masyarakat desa Kebontunggul menerima dan mendukung dalam pelaksanaan KKN-PPM. Terkait dengan pemahaman tema KKN-PPM yaitu tentang Toga ternyata tidak semua masyarakat memahami dengan prosentase $3 \%$ kurang memahami tema. Selain itu, hanya sebagian kecil masyarakat yang kurang mendukung kegiatan KKN-PPM Unesa di desa Kebontunggul dan sebagian besar masyarakat mengetahui kemanfaatan greem house Toga salah satu tekinologi yang diterapkan dimasyarakat sebagai konservasi Toga.

Berdasarkan penilaian kepala desa Kebontunggul mewakili masyarakat bahwa KKN-PPM Unesa 2019 mempunyai nilai lebih dibanding dengan kegiatan $\mathrm{KKN}$ yang dilaksanakan dengan perguruan tinggi lain. Kegiatan KKN-PPM Unesa sebagian besar dilaksanakan dengan program yang terencana. Aktivitas tidak hanya pada tema pokok namun juga terdapat kegiatan sosial lainnya. Kegiatan KKN PPM Unesa 2019 selain berbasis tematik, juga kegiatan sosial masyarakat, seperti: kerja bakti, rapat warga, agustusan, dan lain-lain. Kelancaran koordinasi dengan pihak pemerintah desa dan masyarakat desa salah satu tpolok keberhasilan dari Program KKN-PPM. Hal tersebut digambarkan pada diagram pie pada gambar 8 bahwa $70 \%$ dan $40 \%$ nilai positif dari aktivitas koordinasi dengan pihak terkait.

\section{SIMPULAN DAN SARAN}

\section{Simpulan}

Berdasarkan hasil pembahasan tersebut maka dapat disimpulkan sebagai berikut.

1. Pelaksanaan KKN-PPM Unesa Tahun 2019 tetap mengikuti prinsip-prinsip multidisipliner mulai dari pelaksana, program kegiatan di lapangan. 
2. Teknologi yang diterapkan berupa greenhouse sebagai pusat konservasi Toga.

3. $59 \%$ responden menyatakan sangat setuju, $40 \%$ responden menyatakan setuju, dan $1 \%$ responden menyatakan kurang setuju. Sangat setuju dengan setuju apabila diakumulasi maka pelaksanaan KKN-PPM Unesa 2019 oleh tim pelaksana dosen dan mahasiswa di Kebontunggul dapat dikatakan berhasil (sukses).

\section{Saran}

1. Pengembanga rencana bisnis untuk mempromosikan konservasi toga.

2. Perencanaan produk-produk toga yang dapat dijual di lokasi Eduwisata Konservasi Toga Lembah Mbencirang.

\section{DAFTAR PUSTAKA}

Afin \& Friends. 2013. Daun Dahsyat Pencegah dan Penyembuh Penyakit. Yogyakarta: Penerbit Katahati.

Murtie, Afin. 2014. Cantik Tak Harus Mahal dengan Ramuan Herbal Esensial. Yogyakarta: Cahaya Atma Pustaka

Ningrum, E Kristin \& Mey Murtie. 2012. Aneka Resep Obat Tradisional Bayi, Balita, dan Anak. Jakarta: Dunia Sehat.

Hanum, Musyri'ah dan Tim Redaksi Cemerlang 2013. Pengobatan Tradisional dengan Jamu ala Kraton. Yogyakarta: penerbit Andi.

Harmanto, Ning M. Ahkam Subroto. 2007. Pilih Herbal Tanpa Efek Samping. Jakarta: PT. Elex Media Computer.

Yuliarti, Nurheti. 2014. Sehat, Cantik Bugar dengan Herbal dan Obat Tradisinal. Yogyakarta: Penerbit Andi. 